ARTICLE

https://doi.org/10.1057/s41599-019-0228-7

\title{
Prestige-biased social learning: current evidence and outstanding questions
}

\author{
Ángel V. Jiménez (iD ${ }^{1} \&$ Alex Mesoudi
}

\begin{abstract}
Cultural evolution theory posits that a major factor in human ecological success is our high-fidelity and selective social learning, which permits the accumulation of adaptive knowledge and skills over successive generations. One way to acquire adaptive social information is by preferentially copying competent individuals within a valuable domain (success bias). However, competence within a domain is often difficult or impossible to directly assess. Almost 20 years ago, Henrich and Gil-White (H\&GW) suggested that people use indirect cues of success (e.g., differential levels of attention paid to models by other social learners) as adaptive short-cuts to select models from whom to learn. They called this use of indirect markers of success prestige bias. In this review, we re-visit H\&GW's proposal, examining the evidence amassed since for the adaptiveness and use of prestige bias in humans. First, we briefly outline H\&GW's theory. Second, we analyse whether prestige is associated with competence within valuable domains, which is a crucial assumption underlying the adaptiveness of prestige bias. Third, we discuss prestige cues that people use to infer success (e.g., the amount of voluntary deference and attention received by models). Fourth, we examine the evidence for and against the use of prestige bias in human adults and children. Finally, we point out limitations in the current literature and present new avenues for research on prestige bias.
\end{abstract}

\footnotetext{
${ }^{1}$ Human Behaviour and Cultural Evolution Group (HuBCEG), University of Exeter, Biosciences, Penryn, UK. Correspondence and requests for materials should be addressed to Á.V.J. (email: aj419@exeter.ac.uk)
} 


\section{Introduction}

ultural evolution theory posits that a major factor in human ecological success is our high-fidelity and selective social learning, which permits the accumulation of valuable knowledge and skills over successive generations. One of the most cited types of selective social learning in the cultural evolution literature is to copy the behaviours of individuals highly respected and admired in a social group (i.e., prestigious individuals), known as prestige bias. Almost 20 years ago, Henrich and Gil-White (henceforth H\&GW) developed a theory of the evolution of prestige. The distinctive features of this theory were the consideration of prestige as an alternative route to dominance to attain and maintain high social rank in humans and the relevance attributed to social learning in the evolution of prestige (Henrich and Gil-White, 2001). In this article, we focus on a crucial aspect of H\&GW's theory: the adaptive value and actual use of prestigebiased social learning in humans. In the following, we first outline H\&GW's theory. Second, we analyse whether prestige is associated with competence within valuable domains and older age. Third, we discuss which types of first-order (e.g., age) and second-order (e.g., the distribution of freely conferred deference) cues of prestige people use to infer competence within a valued domain. Fourth, we examine the evidence for and against the use of prestige bias in human adults and children. Finally, we point out limitations in the current literature and present new avenues for research on prestige bias.

\section{Social learning and the evolution of prestige}

Following H\&GW, social rank ${ }^{1}$ is defined as a hierarchy of rewards and/or displays in which individuals at the top enjoy privileges (e.g., preferential access to resources usually without resistance from other in-group members), are influential, and receive deference (i.e., manifestations of respect and submission to their wishes). High social rank is generally desirable and is positively associated with reproductive success in many societies (Betzig, 1988; Chagnon, 1988; J. Hill, 1984; Mealey, 1985; von Rueden et al., 2010; von Rueden and Jaeggi, 2016).

According to $\mathrm{H} \& \mathrm{GW}$, people use, not necessarily consciously, two distinct strategies to acquire and maintain high social rank: dominance and prestige (see also Cheng and Tracy, 2014; Cheng et al., 2013). The dominance strategy involves causing, or threatening to induce, costs to other individuals. If the use of this strategy is successful, this elicits fear in the other individuals, who defer and submit to the wishes of the dominant individual to avoid the potential costs. In contrast, the prestige strategy involves displaying competence in valued domains. If the use of this strategy is successful, this elicits admiration in other individuals, who defer and submit to the wishes of the prestigious individual in order to gain access to, and thus socially learn from, this individual, and to acquire other benefits such as private and public goods (Anderson and Kilduff, 2009a; Cheng and Tracy, 2014; Henrich, 2016; Price and Van Vugt, 2014; Von Rueden et al., 2008). Although the successful use of both strategies leads to receiving deference from other individuals, the key distinction between them is that dominant individuals receive coerced deference, while prestigious individuals receive voluntary (or 'freely-conferred') deference.

$\mathrm{H} \& \mathrm{GW}$ argue that the dominance strategy is phylogenetically ancestral to our species. Humans share this strategy with nonhuman primates (e.g., de Waal, 2000) and other social animals. In contrast, $\mathrm{H} \& \mathrm{GW}$ believe that the prestige strategy is probably unique to humans (but see Chapais, 2015; Garfield et al., 2018; Horner et al., 2010; Kendal et al., 2015 for evidence of prestige in non-human animals). This is because they assume that the evolution of prestige required high-fidelity social learning, which is arguably much more developed in humans than in other animals (Herrmann et al., 2007; Tennie et al., 2009). According to $\mathrm{H} \& \mathrm{GW}$, the selective pressure that drove the evolution of prestige was the need to identify individuals within a group (i.e., not only kin) with "better-than-average" knowledge/skill from whom to learn (but see Barkow, 1989, 2014; Chapais, 2015 for alternative explanations for the evolution of prestige). Copying these individuals within domains such as medicinal plant knowledge or hunting techniques would have led to the acquisition of fitness enhancing knowledge/skills. However, directly inferring superior knowledge/skill is often difficult or costly. For instance, accurately assessing hunting skill is difficult when hunting highly dispersed large-size game in fluctuating environments, in which the variation in caloric returns does not depend exclusively on hunting skill (K. Hill and Kintigh, 2009). Under these circumstances, the use of less direct but more readily available proxies for identifying knowledgeable/skilful individuals is often adaptive. Such proxies include the amount of copying, attention and deference (i.e., costs paid in exchange for access to the model) that individuals freely receive. These prestige cues act as indirect cues of success to select models from whom to learn (Henrich, 2016).

$\mathrm{H} \& \mathrm{GW}$ also formulated a number of predictions derived from their theory of the evolution of prestige, and their theory has inspired a number of related predictions (Table 1, see also Table 2 for a full list of predictions derived from the present review).

\section{Prestige, competence, and age}

H\&GW predict that knowledgeable/skilful individuals tend to acquire prestige (prediction (i) in Table 1). This prediction is based on their assumption that people defer to knowledgeable/ skilful individuals to obtain preferential access to them, and consequently increase valuable social learning opportunities. H\&GW support their prediction with ethnographies that show that prestige is associated with skill/knowledge in valued domains such as hunting (e.g., Holmberg, 1969, pp. 144-145; Lee, 1979, pp. 343-344), supernatural knowledge (e.g., Lee, 1979, pp. 343-344) or combat (e.g., Patton, 2000) in many foraging societies. More formally, this association between prestige and knowledge/skill has been supported by a recent study looking at more than 1000 ethnographical texts on leadership pertaining to 60 cultures contained in the Human Relations Area Files (HRAF) (Garfield et al. 2018). Moreover, H\&GW assumed that prestige and skill/knowledge in valued domains is also positively correlated in modern post-industrial societies as for the case of male adolescents conferring prestige to peers with high athletic skills (Coleman, 1961, pp. 130-135). Similarly, H\&GW predict that older individuals have higher prestige than younger ones, as older individuals have more experience in life and have had time to accumulate greater knowledge and refined skills (prediction (ii) in Table 1). They support this prediction with ethnographic evidence (Maxwell and Silverman, 1970; Simmons, 1945/1970). However, they do not mention modern post-industrial societies, which makes it difficult to know whether they assume that this correlation also holds in such societies.

Reyes-Garcia et al. (2008) tested these predictions with the Tsimane, an indigenous population from the Bolivian Amazon. Participants were asked to list all the important men in the village and say why they were important. Most of the nominations went to people with formal positions (72\%), with the remaining nominations given due to the nominees' personal attributes (12.5\%), including being knowledgeable (2.5\%). The initial measure of prestige was the number of nominations due to personal attributes. The measure of knowledge was ethnobotanical plant knowledge derived using cultural consensus analysis, i.e., the 


\section{Table 1 Predictions about prestige bias derived from the existing literature}

Predictions about prestige, success, age and generosity

i) Skilled/knowledgeable individuals are prestigious ${ }^{a}$

ii) Older individuals tend to be more prestigious than younger ones ${ }^{a}$

iii) Generous individuals tend to be prestigious ${ }^{\mathrm{b}}$

Predictions about behaviours towards knowledgeable/skilful/prestigious individuals

iv) Knowledgeable/skilful/prestigious individuals receive freely conferred deference ${ }^{a}$

v) Knowledgeable/skilful/prestigious individuals are paid more attention to ${ }^{a}$

vi) People seek proximity to knowledgeable/skilful/prestigious individuals ${ }^{a}$

vii) People preferentially copy knowledgeable/skilful individuals ${ }^{a, c}$

Predictions about prestige and social learning

viii) People preferentially copy prestigious over non-prestigious individuals ${ }^{a}$

ix) When success information is absent or difficult to assess, people preferentially copy prestigious individuals ${ }^{\mathrm{d}}$

$x$ ) The use of prestige-biased social learning is more frequent in younger people or people with lack of experience in a given domain

xi) Prestigious individuals are influential/copied, even beyond their domain of expertise ${ }^{a}$

a(Henrich and Gil-White, 2001)

b(Henrich, 2016)

c(Boyd and Richerson, 1985)

d(Atkisson et al., 2012)

${ }^{\mathrm{e}}$ (Little et al., 2015)

\section{Table 2 Predictions about prestige bias derived from the present review}

Predictions about prestige and success (Section 'Prestige, competence, and age')

i) Prestigious individuals tend to be successful either in currently important domains for a social group or in domains which were valued in the recent past

ii) Prestigious individuals only achieve social influence when their domain of prestige is currently valued for a social group

iii) The positive association between perceived success within a domain and prestige will be higher than the positive association between actual success within the same domain and prestige

Predictions about prestige and age (Section 'Prestige, competence, and age')

iv) The association between age and prestige is stronger for domains in which there is no clear evidence of success

v) Older individuals tend to be prestigious in stable environments, while younger individuals tend to be prestigious in rapidly changing environments

vi) A positive relationship between age and prestige only holds for ages prior reaching the peak on skill. Beyond that point the age-prestige

relationship will either plateau or decrease depending on the importance of the domain for a social group

Predictions about prestige and social learning (Section 'Prestige-biased social learning')

vii) The more positively correlated are prestige and success, the more people will use prestige-biased social learning. (Section 'Prestige and success biases')

viii) People will use more prestige-biased social learning when the task is relevant and difficult than when the task is irrelevant and easy for them (Section 'Comparisons between prestige and content biases')

ix) Prestigious individuals will be copied more when the variation in knowledge/skill within a group is large than when this variation is small (Section 'Variation in the use of prestige bias with experience and age')

$x$ ) Cross-domain prestige bias should occur more when cues are noisy within the tested domain than when these cues are clear (Section 'Prestige bias beyond the domain of prestige')

xi) Cross-domain prestige bias should occur when there are domain-general traits like IQ that make people successful across domains (Section 'Prestige bias beyond the domain of prestige')

most common response to whether each of 15 plants had medicinal properties was considered the correct answer. The results did not support either of the two predictions: neither ethnobotanical medicinal knowledge nor age were significantly associated with their measure of prestige.

However, there are several potential explanations for this null finding. When prestige was measured by the raw number of nominations instead of only the nominations due to personal attributes, prestige was positively and significantly associated with having a formal position the previous year and with being born in the 1970s. This latter result might be due to the recent increase in life expectancy in this society, which may have disrupted the predicted association between prestige and age. Alternatively, Reyes-Garcia et al. suggest that the training provided by missionaries to young men to become competent bilinguals (Spanish/ Tsimane) and spread the biblical message gave men born in the 1970s the skills to "navigate between the two worlds" (p. 280).
This might explain their current higher prestige, as opposed to older men with superior ethnobotanical knowledge.

In the same population, Von Rueden et al. (2008) found a strong positive association between hunting ability and respect, i.e., the extent that a person is considered worthy of being admired, which can be seen as equivalent to $H \& G W$ 's prestige. This supports H\&GW's prediction of a positive correlation between knowledge/skill and prestige. Nevertheless, hunting is losing its importance in the studied village due to acculturation and has no effect on community-wide influence, measured as the influence of an individual in the resolution of a dispute during a community-wide meeting. Von Rueden et al. (2008) believe that the social transformation experienced by the Tsimane society might explain why hunting skill is correlated with respect but not with community-wide influence. Conferring respect to people with highly relevant skills in the past might be a residue of "oldfashioned" values, but these values do not predict communitywide influence because these skills are no longer useful. In 
contrast, currently relevant skills (e.g., formal education and Spanish fluency) within this society were significant predictors of community-wide influence (see predictions (i-ii) in Table 2). These authors also found an inverted-U-shaped relationship between age and each of four measures of high rank (success in a physical confrontation, getting one's way in the group, community-wide influence and respect).

Henrich and Henrich (2010) found that, as predicted, prestige (being nominated as a yalewa vuku or 'wise woman') was positively associated with medicinal plant knowledge and age, while controlling for years of education in Fijian society. However, medicinal plant knowledge was assessed only indirectly as the number of nominations of women considered to know the most about medicinal plants (perceived knowledge), rather than direct assessments of actual knowledge. In a different study, Henrich and Broesch (2011) tested the same predictions in three Fijian villages, although also indirectly. The outcome variable there was the probability of an individual being selected as a model from whom to learn in each of three domains (fishing, growing yams and medicinal plants). Perceived success in another domain (cross-domain success) was used to measure prestige. The results supported the prediction of the positive association between prestige and knowledge/skill in different domains. Nevertheless, fishing and yam growing success were much better predictors of prestige (cross-domain success) than plant knowledge. Age was a significant predictor of being selected as a model from whom to learn in the domains of growing yams and medicinal plant knowledge in one of the villages and of fishing and medicinal plant knowledge in the entire sample. Henrich \& Broesch reasoned that, because age is an indirect indicator of success, age is a much more relevant cue in domains such as medicinal plant knowledge in which there does not exist clear evidence of success (see prediction (iv) in Table 2). This potential explanation constitutes an important nuance to the original prediction (prediction (ii) in Table 1) by H\&GW.

In the Hazda, hunter-gatherers in Tanzania, Stibbard-Hawkes et al. (2018) found that hunting prestige (measured using photorankings of hunters) positively predicted three measures of actual hunting success (aim with bow and arrow, pull strength and knowledge of animal vocalisations) but was uncorrelated with a fourth measure (visual acuity). These measures were collected by the researchers by implementing tasks such as an archery contest or using a digital bow pull scale. Similarly to Von Rueden et al. (2008), they found an inverted-U-shaped relationship between age and hunting prestige, and age and hunting success, which might be consequence of the decline of hunting skill after reaching peak skill at 40-55 years of age.

While suggestive, most of these studies do not provide clear evidence to effectively determine whether prestige is positively associated with knowledge/skill and/or age. The most important limitation is that all of the studies (except Stibbard-Hawkes et al., 2018 and von Rouden et al., 2008) used measures of prestige that cannot be easily equated to $\mathrm{H} \& \mathrm{GW}^{\prime}$ s original definition of prestige. The study by Reyes-Garcia et al. (2008) measured the number of nominations of people who were considered "important" within Tsimane villages, which led participants to nominate people with formal leadership positions. Therefore, it confuses power and prestige. Similarly, Henrich and Broesch's (2011) measure of prestige as cross-domain success is also problematic because prestige was initially considered to be domain-specific (H\&GW, p. 170), although with some contradictions ("prestigious individuals are influential even beyond the domain of expertise", H\&GW, p. 184). Another limitation of some of these studies (Henrich and Broesch, 2011; Henrich and Henrich, 2010) is the use of perceived success instead of assessing success directly using objective measures as in the study by Stibbard-Hawkes et al., 2018. Although perceived success and prestige within a domain should be positively correlated given the fact that perceptions of success confer prestige, this does not serve to assess the adaptive role of prestige bias. In order to be adaptive in the first place, prestige should positively correlate with actual success (see prediction (iii) in Table 2). Using the most common answer as a measure of correct knowledge (Reyes-Garcia et al., 2008) is also problematic, as the most frequent answer might be wrong.

To sum up, it is difficult to convincingly say whether there exists an association between prestige and knowledge/skill, and prestige and age. Future research should use better defined, or more direct and relevant, measures of prestige. However, the reviewed studies are useful for refining the research agenda. For example, the inverted U-shaped relationship between prestige and age found by Von Rueden et al. (2008) and Stibbard-Hawkes et al., 2018 is more plausible than a linear relationship if prestige is correlated with skill and there is a decline in physical and cognitive abilities with older age (see H\&GW p. 182, Supplementary Materials in Henrich and Henrich, 2010, p. 4, and prediction (vi) in Table 2). Moreover, older age might be an inefficient cue of prestige in societies where traditional skills/ knowledge have decreased in importance and new skills have become more important for the community (e.g., speaking Spanish to deal with the outside world in Tsimane society, or computer skills in postindustrial technological society). Consequently, older age is a relevant cue of prestige only when the environment changes at a relatively slow rate, such that the correlation between prestige and knowledge is stable across cultural generations (Henrich, 2016). Rapid environmental change, however, disrupts the positive correlation between valuable knowledge and age as it leads to "a high rate of informational obsolescence" (Maxwell and Silverman, 1970, p. 388), which might even lead to prestige being conferred on to younger individuals (Spisak et al. 2014; see prediction (v) in Table 2).

\section{Prestige cues}

To select the best models from whom to learn, social learners can directly assess the competence of different models within a valued domain. For instance, seeing a model successfully hunting large prey or scoring several goals during a football match leads the social learner to infer that the model is successful within those domains. Of course, their success on one day might not be a reliable indicator of their general, sustained success within a domain, but the social learner can update this information when more information is provided (e.g., the results of the next hunting expedition or football match). Nevertheless, assessing competence through this procedure may be costly and noisy. Instead, social learners can use short-cuts either by making inferences from the appearance, personality, material possessions, etc. of the models, which we called first-order cues, or by relying on the behaviours of other social learners towards the models, which we called secondorder cues. Both types of cues can be cheap ways to acquire valuable information, although they can also lead to useless or maladaptive behaviour.

First-order cues. The basis for the usefulness of first-order cues is that these short-cuts are usually positively associated with competence within valuable domains and/or confer prestige due to their close relationship with competence. For instance, the age of a model can be used to infer knowledge and skill as older individuals generally have more experience within a valued domain and, therefore, they can usually provide higher quality information. This cue is especially used and useful for young children as it is less cognitively demanding than other cues such as professed knowledge (Wood et al., 2012). Nevertheless, the usefulness of 
using age to socially learn depends on the social context and the pace of environmental change (see Section 'Prestige, competence, and age').

Generosity has also been linked to prestige (prediction (iii) in Table 1) in experiments (e.g., Flynn et al. 2006; Halevy et al. 2012; Hardy and Van Vugt, 2006; Willer, 2009) and ethnographic observations (e.g., Konečná and Urlacher, 2017; Price, 2003; Radcliffe-Brown, 1964). Because prestigious individuals tend to be both competent and generous (Cheng and Tracy, 2014; Cheng et al. 2010; Henrich, 2016), at least towards members of their ingroup, generosity can be used as a proxy for competence. According to $H \& G W$, this link is probably due to the fact that providing public goods is an excellent way to signal competence and, therefore, to receive further deference, which might be translated into fitness gains. Nevertheless, wealth is often inherited and, therefore, the relationship between being generous (e.g., providing private and public goods to other people) and being competent does not always hold. Moreover, generosity might be valued independently to competence (Bai, 2016) due to the direct benefits (e.g., private and public goods) provided to the group.

The self-assessment of one's ability, which if positive can lead to high self-confidence, is often used as a proxy for competence. In fact, assertive and confident individuals tend to be granted higher social rank within groups (Anderson and Kilduff, 2009b). Although confidence is likely to be associated with competence in many circumstances (e.g., people who do not know about a topic cannot usually communicate their knowledge about it effectively), copying or conferring high social rank to overconfident models (i.e., models who overestimate their knowledge) might not be the best strategy, as other models will outperform them in reality. Similarly, pride displays, which generally occur after an achievement, are often proxies for competence and social rank (Tracy et al., 2013). Nevertheless, the actual relationship with competence might depend on the type of pride display (i.e., authentic vs. hubristic pride, see Cheng et al., 2010). Similarly, job titles within appreciated domains (e.g., doctor) and academic titles conferred by leading universities (e.g., Oxford or Harvard) also act as prestige cues (Burris, 2004; Dalmaso et al., 2012) in postindustrial societies. The same can be said for possessing wealth (Cheng and Tracy, 2013), prestige goods (Plourde, 2008) and wearing particular types of clothing such as suits (Bickman, 1971; DeWall and Maner, 2008; Maner et al., 2008). Nevertheless, it is necessary to emphasise that the identification of these cues as prestige cues has a subjective component because they depend on the values of the social learners and their social group. For instance, wearing a suit might be an inadequate cue of prestige within the punk rock scene, while having a multicolour Mohawk can be used as a prestige cue within this subculture. Likewise, a successful footballer might not be considered prestigious within a group of people who do not like football, as football is not a valuable domain for them. Consequently, research using firstorder prestige cues should ensure that these cues are relevant for the participants.

In summary, although first-order cues have the clear advantage of being less cognitively demanding than assessing the success of a model directly, they are prone to be unreliable for two reasons. First, the relationship of some of these cues (e.g., age, or job titles) with competence depends on the task, context and/or rate of ecological and social environmental change. Second, some selfgenerated first-order cues (e.g., confidence) are open to cheating or deception, especially when prestigious individuals receive material or other benefits. Nevertheless, generosity is a selfgenerated first-order cue which is especially difficult to fake (Barclay, 2013).
Second-order cues. According to H\&GW, individuals give freely conferred deference, pay more attention, seek proximity to, and copy, competent individuals (predictions (iv-vii) in Table 1). Consequently, social learners can use the behaviours of other individuals towards the models to select models from whom to learn. These second-order cues have the advantage of being considerably more difficult to fake and of being regularly updated.

The voluntary payment of costs (freely-conferred deference) in exchange for access to prestigious models (prediction (iv) in Table 1) is a central aspect of H\&GW's theory. H\&GW argue that prestigious individuals are respected, receive unsolicited help, and are freed from some social obligations because social learners use these deference displays to try to grant themselves (not necessarily consciously) preferential access to prestigious individuals to gain valuable social learning opportunities. This preferential access to the models is important as many different skills contribute to the success of a model within a valued domain. H\&GW gave the example of the potential factors involved in hunting success such as being good at making bows, aiming, tracking and approaching prey, as well as more indirect factors such as sleeping well or having an appropriate diet to maintain good eyesight. (Note, however, that if many people show deference to the same individual, the probability of gaining social learning opportunities would be small. Therefore, the adaptive value of paying deference to a highly deferred demonstrator might be minimal.)

Although the study was not conceived to test H\&GW's prediction, van der Vegt et al. (2006) found that students who self-perceived themselves as having low expertise carrying out a research project within four-person groups were more committed (measured with items like "I am very committed to maintain my relationship with X") and provide more help (measured with items like "I assist X with difficult assignments, even when assistance is not directly requested"; "I help X when s/he is running behind in his/her work activities") to individuals perceived as experts within their group. Consistent with H\&GW's prediction, this suggests that deference (helping and commitment) was provided towards perceived experts to incentivise their contribution to the group task and receive help from those experts. Importantly, this reciprocity in the exchange of help and commitment between members with high and low expertise was associated with higher performance in the task. This highlights the adaptive nature of this exchange, which has also been shown theoretically by Panchanathan (2010). Experimental evidence has also shown that high prestige individuals are paid more attention than low prestige individuals (Cheng et al., 2013; Dalmaso et al., 2014; Dalmaso et al., 2012; DeWall and Maner, 2008; Foulsham et al., 2010; Gerpott et al., 2018; Maner et al., 2008; Ratcliff et al., 2011) and that successful individuals tend to be copied (Atkisson et al. 2012; Burdett et al. 2016; McElreath et al., 2008; Mesoudi, 2008; Wood et al., 2013), which provide support for H\&GW's predictions about attention (prediction (v)) and copying (prediction (vii) in Table 1). This makes deferential, attentional and copying cues reliable cues to infer the prestige of an individual in a social group.

To our knowledge, no research has looked directly at the proximity-management strategies of social learners towards high prestige individuals. However, experimental research with WEIRD (Western, Educated, Industrial, Rich and Democratic, see Henrich et al., 2010) samples shows that prestige positively predicts being liked (Brand and Mesoudi, 2018; Cheng et al., 2013), and preferred as a holiday companion, business partner, neighbour (Kruger and Fitzgerald, 2011) and long-term mate (Kruger and Fitzgerald, 2011; Snyder et al., 2008). This provides tentative support for H\&GW's prediction on proximity- 
management towards prestigious individuals (prediction (vi) in Table 1). However, it is possible that this proximity-management might be motivated by other concerns (e.g., coalitional support) than social learning, which is necessary for supporting H\&GW's model. Furthermore, the ethnographical record shows little support for the assumption (prediction (viii) in Table 1) that underpins all these predictions, that is the preferential copying of what prestigious individuals do (Garfield et al., 2018). Nevertheless, this absence of evidence might be motivated by the lack of interest of earlier anthropologists in social learning.

\section{Prestige-biased social learning}

Prestige and success biases. H\&GW predict that prestigious individuals are preferentially copied, which is known as prestige bias (prediction (viii) in Table 1). Importantly, this prediction should only hold when both individual learning and the direct assessment of knowledge/skill of a model are costly or difficult. When the acquisition of knowledge/skill through individual learning is relatively cheap, the use of prestige bias (or social learning in general) is less useful. Similarly, when information about the success of individuals is directly available, people should use this information to select models (success bias) rather than prestige (prediction (ix) in Table 1).

Consequently, Atkisson et al. (2012) compared prestige and success biases in the laboratory. Participants played a computerbased task in which they designed virtual arrowheads over a series of trials (see Mesoudi, 2008; Mesoudi and O'Brien, 2008). Participants could improve their arrowhead by either individual or social learning. There were three hunting seasons. Prestige information (time spent by each of the participants looking at the arrowheads designed by each of the four other participants) was provided to participants throughout the experiment. Success information (score of the four different individuals who used different arrowheads) was only provided in season three. The results supported the prediction about the use of prestige bias: prestige information increased the likelihood of an arrowhead being copied during seasons one and two compared to the other arrowheads. In contrast, the results did not support the prediction about the replacement of prestige bias by success bias when both success and prestige information are available: prestige and success cues were used similarly during season three, even though prestige was not correlated with success in the experiment.

This experiment provides convincing evidence for prestige bias. Nevertheless, it is not clear why participants used prestige and success cues in a similar way in season three. Atkisson et al. (2012) argue that participants use prestige cues to socially learn in their everyday life and this extends to their behaviour in the laboratory. It is also possible that success needs to be observed over longer periods of time to replace prestige bias. Alternatively, perhaps participants were over-trained to use prestige cues in seasons one to two and carried this into season three. A replication adding a second condition, in which success cues are provided during seasons one to two, might clarify this. We might expect participants to learn more easily that success cues are superior to prestige cues in this case. Finally, it would be interesting to systematically manipulate the correlation between prestige and success, to see whether prestige cues are only used when prestige is positively correlated with success (see prediction (vii) in Table 2).

Variation in the use of prestige bias with experience and age. Exploratory analyses by Atkisson et al. (2012) showed that the use of prestige and success biases was greater when participants performed badly in the previous three trials. Another circumstance that might prompt greater use of these biases is the lack of previous experience within a domain. Consequently, the lower level of experience of younger people compared to older people might make younger people more prone to copy prestigious/ successful individuals (prediction (x) in Table 1).

Little et al. (2015) tested this prediction in the domain of mate choice. In an initial experiment, female participants rated the attractiveness of young, artificially-created male faces paired with female faces with different degrees of prestige, which was manipulated by presenting a numeric score of popularity. As predicted (prediction (viii) in Table 1), model popularity positively predicted ratings of male face attractiveness. Moreover, older participants were less likely to be influenced by the popularity of the models than younger participants, consistent with the prediction that prestige bias should vary with experience/ age. However, a limitation of this experiment is that the male faces being rated were all very young. Given evidence that women are less attracted to men who are considerably younger than themselves than men who are of similar age or older (Buss, 1989; Buunk et al. 2001; Schwarz and Hassebrauck, 2012), this may explain the age effect rather than experience. This was addressed by Little et al. in a subsequent experiment, which used real photographs and in which three age groups were used for both participants (16-25, 26-32, 32-61) and stimuli (18-25, 26-32, $32-40)$. Again as predicted, model popularity positively predicted the ratings of attractiveness for the younger group (16-25 years old) but not for the older groups of participants (25-32, 32-61).

Nevertheless, the problem remained: a considerable number of participants in the oldest group $(M=41.6, S D=8.1)$ were still rating exclusively much younger male faces than themselves. Consequently, the interpretation of the findings requires similar caution. Moreover, the effect size was more than double for the interaction between age of the face and participants' age $\left(\eta_{p}^{2}=0.10\right)$ than for the interaction between model popularity and participants' age $\left(\eta_{p}^{2}=0.04\right)$. This suggests that rather than experience-dependent prestige bias, Little et al.'s findings can be explained by the congruency between age of faces and age of participants. Further experiments should ensure that the stimuli are maximally relevant for the participants.

Contrary to Little et al.'s prediction, the two-stage social learning model (Henrich and Broesch, 2011; Henrich and Henrich, 2010; Kline et al., 2013) predicts a greater use of prestige bias with age/experience. As there exists a trade-off between the access costs to different models and the fitnessenhancing information that can be acquired from the models, social learners should first learn from low access cost models (e.g., relatives, neighbours, friends) and later further improve their knowledge/skill by copying prestigious and/or successful models. This updating process would be more noticeable when there is large variation in knowledge/skill within a given domain so that social learners would benefit more from copying high competence models using success or prestige cues. When the variation is small, most social learners would not copy successful/prestigious models because much of the information they can learn from them is shared by almost everyone in the social group and, therefore, they can learn fitness-enhancing knowledge/skills from low access cost models instead (Henrich and Henrich, 2010; see prediction (ix) in Table 2). Mathematical models that include a combination of vertical and oblique transmission have shown that, if some members of each generation use model-based biases (e.g., prestige bias, success bias), fitness-enhancing knowledge/ skills will spread in a population over generations, leading to the emergence of cultural adaptation (Boyd and Richerson, 1985; Henrich, 2004; Powell et al., 2009). This gives plausibility to the adaptive value of the two-stage social learning model.

This pattern seems to be the case in the transmission of adaptive food taboos related to pregnancy and breastfeeding in 
Fijian villages. According to Henrich and Henrich (2010), the pattern of transmission is mainly from older (i.e., mothers, grandmothers, mothers-in-law) to younger (i.e., daughters, granddaughter, daughters-in-law) female relatives. Nevertheless, a substantial minority (almost 25\%) of participants in this study reported to have learnt the taboos from the yalewa vuku (wise women, who were equated to prestigious individuals), or the elders (almost 33\%). Although this gives tentative support for the emergence of cultural adaptation through a combination of vertical and oblique transmission, it is not clear whether prestigebiased transmission was greater at an older than a younger age. The acquisition of relevant skills for wild honey collecting among male Jenu Kuruba in South India also seems to follow the twostage social learning model. According to Demps et al. (2012), most honey collecting knowledge/skill is acquired in this population at younger ages: most people reported to learn tree climbing at six to nine years old, making a smoky torch at 10-15 years old, and cutting honey combs at 16-21 years old. Importantly, most of the knowledge/skills were learnt from relatives (fathers, brothers, and elder kin) but learning from successful individuals and co-workers became more important with age. Nevertheless, the two-stage social learning model is not specific to the use of prestige cues (see Lucas et al., 2016 for further discussion and experimental evidence).

Prestige bias and overimitation. If prestige bias is especially likely to be used when success is difficult to directly assess (see Section 'Social learning and the evolution of prestige'), people should copy irrelevant actions carried out by prestigious individuals when the link between each action and success in the task is not clear for them. Experiments on overimitation, the tendency to copy irrelevant actions to obtain a reward, have looked at whether younger children overimitate high social rank models. McGuigan (2013) conducted an experiment in which five year olds viewed videos with one of four models with high or low social rank performing irrelevant actions (e.g., removing a bolt) and relevant actions (e.g., extracting the sticker with the tool) to obtain a sticker from a transparent box. The high social rank models were the participants' head and class teacher. The low social rank models were a familiar model (a researcher who had carried out research with the children during the previous week) and an unfamiliar model (a totally unacquainted individual for the children). As predicted, children copied irrelevant actions significantly more when they came from the high social rank models than from the low social rank models. Nevertheless, pairwise comparisons only found significant differences between the head teacher and both low rank models. Moreover, the copying of relevant actions was not affected by models' rank. Alternative factors, rather than prestige, might account for the results, as the high rank models were also more familiar to the children and held a position of authority over them.

In contrast, Chudek et al. (2016) obtained findings that cast doubt on importance of model-based biases in overimitation. Children aged two to seven years viewed videos with two female adult models trying to obtain stickers from a puzzle box. In one condition, the models had low or high prestige, which was manipulated by showing two individuals carefully looking at the actions performed by one model (high prestige) while ignoring the actions of the other model (low prestige). In another condition, the models had high or low success, which was manipulated by the models either saying they obtained five (high success) or zero (low success) stickers. While overimitation generally increased with age, there was no selectivity at any age: the children were equally likely to overimitate successful and unsuccessful, and prestigious and nonprestigious, models. Importantly, these negative results were found using models who were not familiar to the children and who did not have a position of authority over them, suggesting that these factors might have driven the selective overimitation in McGuigan's (2013) experiment.

Prestige bias beyond the domain of prestige. H\&GW predict that prestigious individuals are influential beyond their domain of expertise (prediction (xi) in Table 1). This prediction is based on the following assumption: as it is difficult or costly to identify the factors that make someone successful within a valued domain, natural selection should have favoured a general-copying bias towards the prestigious, in the hope that at least one of the many characteristics that are copied are causally related to success. For instance, many factors might lead to being a successful hunter (tracking skill, ability and materials use to make bows, sleeping well, etc.) and, consequently, a general copying bias of all of these traits associated with the prestigious might be adaptive, at the occasional cost of copying neutral or maladaptive traits (e.g., wearing a magic charm, or being tattooed). This general social learning bias towards prestigious individuals might help to explain why the opinions of prestigious individuals within a given domain (e.g., acting or singing in Western society or hunting in a foraging society) are influential in other domains (e.g., Arnocky et al. 2018; Jackson and Darrow, 2005; Lee, 1979, p. 343; Radcliffe-Brown, 1964, p. 64; Smith and Bird, 2000). Another possibility not considered by $\mathrm{H} \& \mathrm{GW}$ is that there exist domaingeneral traits that are likely to lead to success in multiple domains, such as having an inner locus of control, intrinsic motivation, general intelligence/IQ, or being perseverant and selfdisciplined. These domain-general traits might explain in part the success of some celebrities such as Will Smith (acting, rapping) or Arnold Schwarzenegger (bodybuilding, acting, politics) across multiple domains (although being famous itself may also have helped them to achieve success in other domains). Nevertheless, a cross-domain social learning bias towards the prestigious might sometimes cause the acquisition of maladaptive information and, consequently, it should be expected that the influence of prestigious individuals is larger within their domain of prestige.

To test this, Chudek et al. (2012) conducted two studies with three to four years olds. The manipulation of prestige involved varying the degree of attention that two different models received from other individuals. The models then showed a preference for one of two foods, drinks, artefacts or labels for novel objects. Afterwards, children's preferences for the same item pairs were tested. The results for the first study supported prestige-biased social learning (prediction (viii) in Table 1), as children were more likely to share the preferences of the prestigious model over the non-prestigious model. The second study in which the models displayed preferences only in one of two domains (food or artefacts) also provided support for the prestige-biased social learning hypotheses, but confined within the domain of prestige. That is, children followed the preference of the prestigious model only for the specific domain in which they saw that model exhibit preferences. Consequently, this study did not provide support for H\&GW's prediction of cross-domain prestige-biased social learning. Future studies might benefit from studying more directly the two aforementioned mechanisms that favour crossdomain prestige bias, as they make specific and as-yet untested predictions. From the first mechanism (general copying bias) it follows that cross-domain prestige bias should occur when cues are noisy within the tested domain (see prediction (x) in Table 2). From the second mechanism (cross-domain general ability) it follows that cross-domain prestige bias should occur when there are domain-general traits like IQ that make people successful across domains (see prediction (xi) in Table 2). 
Comparisons between prestige and content biases. Although theoretically prestige biased social learning is generally adaptive, so are other social learning biases, and it is instructive to compare people's use of prestige bias relative to other biases. Acerbi and Tehrani (2018) conducted two studies that compare the strength of content and prestige in cultural transmission. Content biases occur when certain types of material are preferentially transmitted, in contrast to model-based biases such as prestige bias where characteristics of the model are used. Acerbi and Tehrani (2018) chose the topic of quotations because it is a domain in which both content (the message of the quote) and prestige (e.g., frequent misattribution of quotes to famous people) are relevant. First, participants rated a series of unattributed quotes for their likeability, i.e., content. Then, they tested whether quotes associated with famous (i.e., prestigious) individuals (e.g., Vincent Van Gogh) were more liked than the same quotes associated with non-famous individuals invented by the researchers (e.g., Winston Perkins). The results showed no statistical difference in liking ratings between quotes associated with the high and low prestige individuals. Instead, liking was significantly predicted by the original likeability ratings of the quotes when unattributed. This suggests that the content of the quotations is more important than the attributed authorship of the quotation.

Acerbi and Tehrani argue that the lack of evidence for prestige bias in their study might have been because the task did not require any kind of expertise. Furthermore, participants did not obtain higher or lower rewards for preferring some quotations over others. Consequently, the use of prestige bias was not useful here as participants could easily assess the likability of the quotes by themselves without any cost (see prediction (viii) in Table 2). Alternatively, people might have assumed that the "low prestige" names were "high prestige" too but that they had not heard of them before.

As was argued in section 'Variation in the use of prestige bias with experience and age', the usefulness of prestige bias (and social learning in general) should depend on people's expertise. When people lack experience within a given domain, they should benefit more from using prestige cues to select models from whom to learn (prediction (ix) in Table 1). However, the opposite can also be true, i.e., prestige bias is used more by those with high expertise, when the domain is more relevant for experts than non-experts, and when the task is more difficult for experts than non-experts. This is what Verpooten and Dewitte (2017) found for the appreciation of modern art. Like Acerbi and Tehrani, they used a subjective task in which there was no objective correct or incorrect answer. Laypeople and art experts were shown portraits of female faces, which varied in attractiveness (moderate vs. high attractiveness). In one condition, participants were shown these pictures without any additional information. In another condition, participants were told that the pictures belonged to a collection of a prestigious museum in New York (MoMA). As predicted, laypeople's appreciation was guided by the content of the pictures, showing more appreciation for the highly attractive faces than the moderately attractive faces with little influence of the prestige manipulation. As was also predicted, experts showed more appreciation for the pictures associated with the prestigious museum. This relationship was mediated by admiration towards the artists, which is consistent with H\&GW's theory (see Section 'Social learning and the evolution of prestige'). Surprisingly, they also found that experts appreciated more the moderately attractive faces than the highly attractive faces. In another study, Verpooten (2018) used real artworks from MoMA, which depicted animate (e.g., pig) or inanimate (e.g., chair) objects. According to evolutionary psychologists (New et al., 2007), people have an evolved preference for animate over inanimate objects, which the authors predicted would guide the behaviour of non-experts. Consistent with this, there was an overall preference for animate over inanimate objects. Again, however, this was moderated by expertise. The greater the expertise of the participants, the less the participants appreciated the animate over the inanimate artworks, to the extent the preferences reversed in the top experts. Verpooten and Dewitte (2017), inspired by previous work (Boyd and Richerson, 1985; Prum, 2013), argue that the experts' deviations in artwork preferences from evolved aesthetic preferences might be due to a runaway process analogous to a runway sexual selection in which the trait (here, artworks) coevolves with preferences within a population of art experts.

Although the research covered in this section is interesting with respect to the general phenomenon of prestige, it is not clear how the likability of quotes or artworks is related to social learning. Although a greater appreciation of a cultural item probably leads to the greater transmissibility of that item, this may not always be the case. Disgust-inducing information, for instance, is not particularly liked, yet several studies have shown that it has a transmission advantage (Eriksson and Coultas, 2014; Heath et al., 2001; Miton et al., 2015), at least, in WEIRD samples (Eriksson et al., 2016). For instance, an offensive comment on Twitter (e.g., one that is overtly racist) or Marcel Duchamp's Fountain might be disgusting and be disliked by many people, but this in itself could contribute to these items' greater transmission by commenting on them or drawing attention to them. Future studies should test the differential effects of the content of the information and the prestige associated to the source by designing experiments that measure transmission in a more direct way using, for instance, experimental paradigms such as transmission chains (Bartlett, 1932; Mesoudi, 2007) and choose-to-transmit (Eriksson and Coultas, 2014; Heath et al., 2001; Stubbersfield et al., 2014) and choose-to-receive (Eriksson and Coultas, 2014; Stubbersfield et al., 2014) methods.

Final remarks and future directions. In this article, we have reviewed the evidence amassed for the adaptiveness and use of prestige bias in human adults and children since the publication of H\&GW's influential paper and suggested new predictions and research questions (see Table 2). Although H\&GW predicted that prestige is positively correlated with both skill/knowledge within valued domains and age (predictions (i-ii) in Table 1), the specific tests of these claims inspired by H\&GW's theory suggest a more complex picture. Above all, the positive association between prestige and both knowledge/skill and age heavily depends on the stability of the social and ecological environment. When there is rapid social change, the skills/knowledge that were important and valuable in the past might not be any longer. Nevertheless, people might still confer prestige according to old-fashioned values, which would disrupt the predicted positive correlation between prestige and knowledge/skill. Alternatively, people might confer prestige according to new values that confer importance to the skills that are relevant nowadays. In this case, if the researchers measure the correlation between prestige and a particular domain of knowledge/skill that has lost its importance within a society, the predicted positive association between prestige and knowledge/skill would be disrupted (see predictions (i-iii) in Table 2). The same can be said about the predicted positive correlation between prestige and age. Age is a good cue of knowledge/skill when the social and ecological environment is relatively stable and life expectancy does not go much beyond an age at which the degradation of cognitive and physical skills starts. When there is rapid environmental change, older age might be an inadequate cue to select models from whom to learn and sometimes even younger models might be preferred. Moreover, the degradation of 
cognitive and physical skills with age might moderate the positive association between age and knowledge/skill and favour a plateau or a decline at older age. Future research should explore how social and ecological change and the age-dependency in skill/ knowledge within different domains affects the association between prestige, knowledge/skill and age (see predictions ( $\mathrm{v}$-vi) in Table 2).

The evidence reviewed in this article provides mixed support for the use of prestige-biased social learning in both human adults and children. However, few studies have examined this and further research is needed to clarify which factors lead to variation in the use of prestige-biased social learning. The difficulty of the task, the relevance of the domain for the individuals and the benefits and costs associated with the task seem to be important factors influencing the use of prestigebiased social learning (see prediction (viii) in Table 2). In general, easy tasks, tasks that are not relevant for participants and tasks that do not provide incentives to perform well or avoid costs (e.g., monetary rewards or costs) seem not to stimulate the use of prestige-biased social learning (Acerbi and Tehrani, 2018). Other factors taken into account in the literature, such as experience and age (Little et al., 2015) seem to be important when they affect task difficulty, the relevance of the domain for the participants and potential gains or costs of the task for the participants. For instance, expertise leads to a greater use of prestige-biased social learning when the task is more relevant for the experts but the task is still difficult for them (Verpooten and Dewitte, 2017). Similarly, younger individuals use more prestige-biased social learning than older individuals when the task is more relevant for them (Little et al., 2015). Moreover, when there is little variation in knowledge/skill in a group, it is more adaptive to learn from low access cost models than from costly prestigious models (Henrich and Henrich, 2010; see prediction (ix) in Table 2).

Another factor that influences the use of prestige-biased social learning is the availability of alternative social learning biases, e.g., success or content biases. When success information is provided, this information should be preferentially used over prestige information (prediction (ix) in Table 1). However, this was not found in the sole experiment comparing prestige with success bias (Atkisson et al., 2012), although this is a single study. Both direct and conceptual replications are needed to gain confidence in this result. Content bias was stronger than prestige bias in another study (Acerbi and Tehrani, 2018), but this might depend on the domain and the factors mentioned above (i.e., task difficulty, relevance for the individual, and benefits and costs associated with the task). Variation in some of these factors (e.g., the relevance for the participants) might lead some participants (e.g., non-experts) to make use of content biases, while other participants (e.g., experts) to employ prestige-biased social learning (Verpooten and Dewitte, 2017).

It is also possible that prestige biased social learning has different effects on different measures of influence, e.g., recall, likability, behavioural influence, willingness to transmit and receive information. To the extent these measures of influence affect task difficulty, relevance for the participants or the benefits/ costs associated with tasks, it seems plausible that the different measures would be a source of variation in the use of prestige and other social learning biases. For instance, although one recent study found that anti-vaccination messages are not better transmitted per se, exploratory analyses showed that when antivaccination messages are provided by doctors (i.e., a prestigious source within a relevant domain) these types of messages are especially powerful in influencing people's vaccination-related decisions (Jiménez et al., 2018). Similarly, although people might be able to appreciate the content of certain pieces of information (e.g., quotes, news, artworks, etc.) independent of the prestige of the source of the information, they might be more influenced by prestige cues when they want to achieve influence over other people's behaviour (e.g., by quoting a prestigious source of information), get personal or social benefits (e.g., choosing artworks to be displayed in their own town) or they have to decide whether to learn more about a topic or transmit the information about the topic to other people. Therefore, research on prestige-biased social learning might benefit from comparing the influence of prestige cues on different types of outcomes.

Although H\&GW predicted that prestige-biased social learning is cross-domain such that prestige in one domain bleeds across to other domains (prediction (xi) in Table 1), the only experiment testing this hypothesis found that prestige-biased social learning is stronger within domains (Chudek et al., 2012). Nevertheless, anecdotal evidence (e.g., the influence of the opinions of celebrities in domains in which they are not experts) suggests that cross-domain prestige-biased social learning occurs to some extent. In small-scale societies, it is likely that prestigious individuals are relatively skilful/knowledgeable across multiple domains and, consequently, a cross-domain prestige bias would be adaptive (Acerbi, 2016), albeit leading to the occasional acquisition of irrelevant or even maladaptive information. However, the risks of cross-domain prestige-biased social learning seem considerably higher in the digital era in which, for example, young people in developing countries might be more influenced by American pop singers, Hollywood celebrities or leaders of terrorist groups than by the nearby adults who have relevant skills for their environment (Barkow et al., 2012). Consequently, studying to what extent the digital media have subverted the adaptive role of prestige-biased social learning seems a productive new avenue for research on prestige and social learning (Acerbi, 2016; Barkow et al., 2012).

$\mathrm{H} \& \mathrm{GW}$ predicted that information provided by prestigious individuals is more memorable, but this question has not been studied yet. If $\mathrm{H} \& \mathrm{GW}$ are correct and prestige-based hierarchies evolved to select fitness-enhancing models from whom to learn, prestige-biased social learning should strongly affect human memory. However, it is possible that the effects of prestige on memory are just the consequence of the preferential attention that prestigious individuals receive (see Section 'Second-order cues'). Therefore, studies exploring how prestige cues affect memory should look at how differential attention towards prestigious and non-prestigious individuals affects memorability (e.g., by using eye-tracking).

In conclusion, $\mathrm{H} \& \mathrm{GW}$ 's theory of the evolution of prestige has generated a great deal of research and this research has stimulated new research questions and predictions. Although the evidence reviewed here suggest that prestige-bias social learning is employed in at least some contexts, further research will need to determine the precise circumstances in which people use prestige cues to learn socially, and when the use of these cues is adaptive.

\section{Data availability}

Data sharing is not applicable to this paper as no datasets were analysed or generated.

Received: 16 October 2018 Accepted: 14 January 2019

Published online: 19 February 2019

\section{Notes}

1 In reality, H\&GW use the word "status". We prefer the word "social rank" as there is an emerging consensus in the literature to use social status and prestige as synonyms (e.g., Anderson et al. 2015; Cheng and Tracy, 2014) or as closely related terms (e.g., Blader and Chen, 2014) 


\section{References}

Acerbi A (2016) A cultural evolution approach to digital media. Front Human Neurosci 10(636). https://doi.org/10.3389/fnhum.2016.00636

Acerbi A, Tehrani JJ (2018) Did Einstein really say that? Testing content versus context in the cultural selection of quotations. J Cogn Cult 18(3-4):293-311. https://doi.org/10.1163/15685373-12340032

Anderson C, Hildreth JAD, Howland L (2015) Is the desire for status a fundamental human motive? A review of the empirical literature. Psychol Bull 141 (3):574-601. https://doi.org/10.1037/a0038781

Anderson C, Kilduff GJ (2009a) The pursuit of status in social groups. Curr Dir Psychol Sci 19(5):205-209

Anderson C, Kilduff GJ (2009b) Why do dominant personalities attain influence in face-to-face groups? The competence-signaling effects of trait dominance. J Personal Social Psychol 96(2):491-503. https://doi.org/10.1037/a0014201

Arnocky S, Bozek E, Dufort C, Rybka S, Hebert R (2018) Celebrity opinion influences public acceptance of human evolution. Evolut Psychol 16 (3):1474704918800656. https://doi.org/10.1177/1474704918800656

Atkisson C, O'Brien MJ, Mesoudi A (2012) Adult learners in a novel environment use prestige-biased social learning. Evolut Psychol 10(3):519-537

Bai F (2016) Beyond dominance and competence: a moral virtue theory of status attainment. Personal Social Psychol Rev 21(3):203-227. https://doi.org/ $10.1177 / 1088868316649297$

Barclay P (2013) Strategies for cooperation in biological markets, especially for humans. Evol Human Behav 34(3):164-175

Barkow JH (1989) Darwin, sex and status. University of Toronto Press, Toronto (Canada)

Barkow JH (2014) Prestige and the ongoing process of culture revision. In: Cheng JT, Tracy JL, Anderson C (eds) The psychology of social status. Springer New York, New York, p 29-45

Barkow JH, O'Gorman R, Rendell L (2012) Are the new mass media subverting cultural transmission? Rev General Psychol 16(2):121-133. https://doi.org/ $10.1037 / \mathrm{a} 0027907$

Bartlett FC (1932) Remembering: a study in experimental and social psychology. Cambridge University Press, Cambridge

Betzig L (1988) Despotism and differential reproduction: a Darwinian view of history, vol. 14, Aldine Publishing Co., New York

Bickman L (1971) The effect of social status on the honesty of others. J Social Psychol 85(1):87-92. https://doi.org/10.1080/00224545.1971.9918547

Blader SL, Chen Y-R (2014) What's in a name? Status, power, and other forms of social hierarchy. In: Cheng JT, Tracy JL, Anderson C (eds) The psychology of social status. Springer New York, New York, p 71-95

Boyd R, Richerson PJ (1985) Culture and the evolutionary process. University of Chicago Press, Chicago

Brand CO, Mesoudi A (2018) Prestige and dominance based hierarchies exist in naturally occurring human groups, but are unrelated to task-specific knowledge. Prepint at https://psyarxiv.com/s32rv/

Burdett ER, Lucas AJ, Buchsbaum D, McGuigan N, Wood LA, Whiten A (2016) Do children copy an expert or a majority? Examining selective learning in instrumental and normative contexts. PLOS ONE 11(10):e0164698

Burris V (2004) The academic caste system: prestige hierarchies in $\mathrm{PhD}$ exchange networks. Am Sociol Rev 69(2):239-264. https://doi.org/10.1177/ 000312240406900205

Buss DM (1989) Sex differences in human mate preferences: evolutionary hypotheses tested in 37 cultures. Behav Brain Sci 12(1):1-14. https://doi.org/ 10.1017/S0140525X00023992

Buunk BP, Dijkstra P, Kenrick DT, Warntjes A (2001) Age preferences for mates as related to gender, own age, and involvement level. Evol Human Behav 22 (4):241-250. https://doi.org/10.1016/S1090-5138(01)00065-4

Chagnon N (1988) Life histories, blood revenge, and warfare in a tribal population. Science 239(4843):985-992. https://doi.org/10.1126/science.239.4843.985

Chapais B (2015) Competence and the evolutionary origins of status and power in humans. Human Nat Interdiscip Biosoc Perspect 26(2):161-183. https://doi. org/10.1007/s12110-015-9227-6

Cheng JT, Tracy JL (2013) The impact of wealth on prestige and dominance rank relationships. Psychol Inq 24(2):102-108. https://doi.org/10.1080/ 1047840X.2013.792576

Cheng JT, Tracy JL (2014) Toward a unified science of hierarchy: dominance and prestige are two fundamental pathways to human social rank. In J. T. Cheng, J. L. Tracy, \& C. Anderson (Eds.), The Psychology of SocialStatus (pp. 3-27). New York, NY: Springer New York. https://doi.org/10.1007/978-1-49390867-7_1

Cheng JT, Tracy JL, Foulsham T, Kingstone A, Henrich J (2013) Two ways to the top: evidence that dominance and prestige are distinct yet viable avenues to social rank and influence. J Personal Social Psychol 104(1):103-125. https:// doi.org/10.1037/a0030398

Cheng JT, Tracy JL, Henrich J (2010) Pride, personality, and the evolutionary foundations of human social status. Evol Human Behav 31(5):334-347. https://doi.org/10.1016/j.evolhumbehav.2010.02.004
Chudek M, Baron AS, Birch S (2016) Unselective overimitators: the evolutionary implications of children's indiscriminate copying of successful and prestigious models. Child Dev 87(3):782-794. https://doi.org/10.1111/ cdev.12529

Chudek M, Heller S, Birch S, Henrich J (2012) Prestige-biased cultural learning: bystander's differential attention to potential models influences children's learning. Evol Human Behav 33:46-56

Coleman JS (1961) The adolescent society: the social life of the teenager and its impact on education. Free Press; Collier-Macmillan, New York

Dalmaso M, Galfano G, Coricelli C, Castelli L (2014) Temporal dynamics underlying the modulation of social status on social attention. PLOS ONE 9(3) https://doi.org/10.1371/journal.pone.0093139

Dalmaso M, Pavan G, Castelli L, Galfano G (2012) Social status gates social attention in humans. Biol Lett 8(3):450-452. https://doi.org/10.1098/ rsbl.2011.0881

de Waal F (2000) Chimpanzee politics: power and sex among apes. Johns Hopkins University Press, Baltimore

Demps K, Zorondo-Rodríguez F, García C, Reyes-García V (2012) Social learning across the life cycle: cultural knowledge acquisition for honey collection among the Jenu Kuruba, India. Evol Human Behav 33(5):460-470. j. evolhumbehav.2011.12.008

DeWall CN, Maner JK (2008) High status men (but not women) capture the eye of the beholder. Evolut Psychol 6(2):328-341

Eriksson K, Coultas JC (2014) Corpses, maggots, poodles and rats: emotional selection operating in three phases of cultural transmission of urban legends. J Cogn Cult 14(1-2):1-26

Eriksson K, Coultas JC, de Barra M (2016) Cross-cultural differences in emotional selection on transmission of information. J Cogn Cult 16(1-2):122-143. https://doi.org/10.1163/15685373-12342171

Flynn FJ, Reagans RE, Amanatullah ET, Ames DR (2006) Helping one's way to the top: self-monitors achieve status by helping others and knowing who helps whom. J Personal Social Psychol 91(6):1123-1137. https://doi.org/10.1037/ 0022-3514.91.6.1123

Foulsham T, Cheng JT, Tracy J, Henrich J, Kingstone A (2010) Gaze allocation in a dynamic social situation of social status and speaking. Cognition 117:319-331

Garfield Z, Hubbard R, Hagen HE (2019) Evolutionary models of leadership: tests and synthesis. Human Nat 30(1)

Garfield ZH, von Rueden C, Hagen E (2018) The evolutionary anthropology of political leadership. The Leadership Quarterly. https://doi.org/10.1016/j. leaqua.2018.09.001

Gerpott FH, Lehmann-Willenbrock N, Silvis JD, Van Vugt M (2018) In the eye of the beholder? An eye-tracking experiment on emergent leadership in team interactions. The Leadership Quarterly. https://doi.org/10.1016/j. leaqua.2017.11.003

Halevy N, Chou EY, Cohen TR, Livingston RW (2012) Status conferral in intergroup social dilemmas: behavioral antecedents and consequences of prestige and dominance. J Personal Social Psychol 102(2):351-366. https://doi.org/ 10.1037/a0025515

Hardy CL, Van Vugt M (2006) Nice guys finish first: the competitive altruism hypothesis. Personal Social Psychol Bull 32(10):1402-1413. https://doi.org/ $10.1177 / 0146167206291006$

Heath C, Bell C, Sternberg E (2001) Emotional selection in memes: the case of urban legends. J Personal Social Psychol 81(6):1028-1041

Henrich J (2004) Demography and cultural evolution: how adaptive cultural processes can produce maladaptive losses: the Tasmanian case. Am Antiq 69 (2):197-214. https://doi.org/10.2307/4128416

Henrich J (2016) The secret of our success: how culture is driving human evolution, domesticating our species, and making us smarter. Princeton University Press, Princeton, New Jersey

Henrich J, Broesch J (2011) On the nature of cultural transmission networks: evidence from Fijian villages for adaptive learning biases. Philos Trans R Soc B-Biol Sci 366(1567):1139-1148. https://doi.org/10.1098/ rstb. 2010.0323

Henrich J, Gil-White FJ (2001) The evolution of prestige: freely conferred deference as a mechanism for enhancing the benefits of cultural transmission. Evol Human Behav 22(3):165-196. https://doi.org/10.1016/S1090-5138(00) 00071-4

Henrich J, Heine SJ, Norenzayan A (2010) The weirdest people in the world? Behav Brain Sci 33(2-3):61-83. https://doi.org/10.1017/s0140525x0999152x

Henrich J, Henrich N (2010) The evolution of cultural adaptations: fijian food taboos protect against dangerous marine toxins. Proc R Soc B. https://doi.org/ 10.1098/rspb.2010.1191

Herrmann E, Call J, Hernandez-Lloreda MV, Hare B, Tomasello M (2007) Humans have evolved specialized skills of social cognition: the cultura intelligence hypothesis. Science 317(5843):1360-1366. https://doi.org/ $10.1126 /$ science.1146282

Hill J (1984) Prestige and reproductive success in man. Evol Human Behav 5 (2):77-95. https://doi.org/10.1016/0162-3095(84)90011-6 
Hill K, Kintigh K (2009) Can anthropologists distinguish good and poor hunters? Implications for hunting hypotheses, sharing conventions, and cultural transmission. Curr Anthropol 50(3):369-378. https://doi.org/ $10.1086 / 597981$

Holmberg AR (1969) Nomads of the long bow: the Siriono of Eastern Bolivia. American Museum for Natural History, New York

Horner V, Proctor D, Bonnie KE, Whiten A, de Waal FBM (2010) Prestige affects cultural learning in chimpanzees. PLOS ONE 5(5) https://doi.org/10.1371/ journal.pone. 0010625

Jackson DJ, Darrow TIA (2005) The influence of celebrity endorsements on young adults' political opinions. Harv Int J Press/Polit 10(3):80-98. https://doi.org/ 10.1177/1081180X05279278

Jiménez ÂV, Stubbersfield JM, Tehrani JJ (2018) An experimental investigation into the transmission of antivax attitudes using a fictional health controversy Social Sci Med 215:23-27. https://doi.org/10.1016/j.socscimed.2018.08.032

Kendal R, Hopper LM, Whiten A, Brosnan SF, Lambeth SP, Schapiro SJ, Hoppitt W (2015) Chimpanzees copy dominant and knowledgeable individuals: implications for cultural diversity. Evol Human Behav 36(1):65-72. https:// doi.org/10.1016/j.evolhumbehav.2014.09.002

Kline MA, Boyd R, Henrich J (2013) Teaching and the life history of cultural transmission in Fijian villages. Human Nat 24(4):351-374. https://doi.org/ 10.1007/s12110-013-9180-1

Konečná M, Urlacher SS (2017) Male social status and its predictors among Garisakang forager-horticulturalists of lowland Papua New Guinea. Evol Human Behav 38(6):789-797. https://doi.org/10.1016/j. evolhumbehav.2017.05.005

Kruger DJ, Fitzgerald CJ (2011) Reproductive strategies and relationship preferences associated with prestigious and dominant men. Personal Individ Differ 50(3):365-369. https://doi.org/10.1016/j.paid.2010.10.022

Lee RB (1979) The!Kung San: men, women, and work in a foraging society. Cambridge University Press, Cambridge

Little AC, Caldwell CA, Jones BC, DeBruine LM (2015) Observer age and the social transmission of attractiveness in humans: Younger women are more influenced by the choices of popular others than older women. Br J Psychol 106 (3):397-413. https://doi.org/10.1111/bjop.12098

Lucas AJ, Burdett, ERR, Burgess V, Wood LA, McGuigan N, Harris PL, Whiten A (2016) The development of selective copying: children's learning from an expert versus their mother. Child Develop 88(6):2026-2042. https://doi.org/ $10.1111 /$ cdev.12711

Maner JK, DeWall CN, Gailliot MT (2008) Selective attention to signs of success: social dominance and early stage interpersonal perception. Personal Social Psychol Bull 34(4):488-501. https://doi.org/10.1177/0146167207311910

Maxwell RJ, Silverman P (1970) Information and esteem: cultural considerations in the treatment of the aged. Aging Human Dev 1(4):361-392. https://doi.org/ 10.2190/AG.1.4.g

McElreath R, Bell AV, Efferson C, Lubell M, Richerson PJ, Waring T (2008) Beyond existence and aiming outside the laboratory: estimating frequencydependent and pay-off-biased social learning strategies. Philos Trans R Soc B 363(1509):3515-3528. https://doi.org/10.1098/rstb.2008.0131

McGuigan N (2013) The influence of model status on the tendency of young children to over-imitate. J Exp Child Psychol 116(4):962-969. https://doi.org/ 10.1016/j.jecp.2013.05.004

Mealey L (1985) The relationship between social status and biological success: a case study of the Mormon religious hierarchy. Ethol Sociobiol 6(4):249-257. https://doi.org/10.1016/0162-3095(85)90017-2

Mesoudi A (2007) Using the methods of experimental social psychology to study cultural evolution. J Social, Evolut, Cult Psychol 1(2):35

Mesoudi A (2008) An experimental simulation of the "copy-successful-individuals" cultural learning strategy: adaptive landscapes, producer-scrounger dynamics, and informational access costs. Evol Human Behav 29(5):350-363. https://doi.org/10.1016/j.evolhumbehav.2008.04.005

Mesoudi A, O'Brien MJ (2008) The cultural transmission of Great Basin projectilepoint technology I: an experimental simulation. Am Antiq 73:3-28

Miton H, Claidiere N, Mercier H (2015) Universal cognitive mechanisms explain the cultural success of bloodletting. Evol Human Behav 36(4):303-312. https://doi.org/10.1016/j.evolhumbehav.2015.01.003

New J, Cosmides L, Tooby J (2007) Category-specific attention for animals reflects ancestral priorities, not expertise. Proc Natl Acad Sci 104(42):16598

Panchanathan K (2010) The evolution of prestige-biased transmission. Working paper. https://faculty.missouri.edu/ panchanathank/papers/inPrep/ PanchanathanPrestige.pdf

Patton JQ (2000) Reciprocal altruism and warfare: a case from the Ecuadorian Amazon. In: Cronk L, Chagnon N, Irons W (Eds.) Adaption and Human Behavior. An anthropological perspective. Aldine de Gruyter, New York, p $417-436$

Plourde AM (2008) The origins of prestige goods as honest signals of skill and knowledge. Human Nat 19(4):374-388. https://doi.org/10.1007/s12110-0089050-4
Powell A, Shennan S, Thomas MG (2009) Late pleistocene demography and the appearance of modern human behavior. Science 324(5932):1298

Price ME (2003) Pro-community altruism and social status in a Shuar village. Human Nat- Interdiscip Biosoc Perspect 14(2):191-208. https://doi.org/ 10.1007/s12110-003-1003-3

Price ME, Van Vugt M (2014) The evolution of leader-follower reciprocity: the theory of service-for-prestige. Front Human Neurosci 8(363) https://doi.org/ $10.3389 /$ fnhum. 2014.00363

Prum RO (2013) Coevolutionary aesthetics in human and biotic artworlds. Biol Philos 28(5):811-832. https://doi.org/10.1007/s10539-013-9389-8

Radcliffe-Brown AR (1964) The Andaman islanders. Free Press of Glencoe, New York

Ratcliff NJ, Hugenberg K, Shriver ER, Bernstein MJ (2011) The allure of status: high-status targets are privileged in face processing and memory. Personal Social Psychol Bull 37(8):1003-1015. https://doi.org/10.1177/ 0146167211407210

Reyes-Garcia V, Molina JL, Broesch J, Calvet L, Huanca T, Saus J, McDade TW (2008) Do the aged and knowledgeable men enjoy more prestige? A test of predictions from the prestige-bias model of cultural transmission. Evol Human Behav 29(4):275-281. https://doi.org/10.1016/j. evolhumbehav.2008.02.002

Schwarz S, Hassebrauck M (2012) Sex and age differences in mate-selection preferences. Human Nat 23(4):447-466. https://doi.org/10.1007/s12110-0129152-x

Simmons LW (1945) The role of the aged in primitive society. Archon Books, Hamden, 1970

Smith EA, Bird RLB (2000) Turtle hunting and tombstone opening: public generosity as costly signaling. Evol Human Behav 21(4):245-261. https://doi.org/ 10.1016/S1090-5138(00)00031-3

Snyder JK, Kirkpatrick LA, Barrett HC (2008) The dominance dilemma: do women really prefer dominant mates? Personal Relatsh 15(4):425-444. https://doi. org/10.1111/j.1475-6811.2008.00208.x

Spisak BR, Grabo AE, Arvey RD, van Vugt M (2014) The age of exploration and exploitation: Younger-looking leaders endorsed for change and older-looking leaders endorsed for stability. Leadersh Q 25(5):805-816. https://doi.org/ 10.1016/j.leaqua.2014.06.001

Stibbard-Hawkes DNE, Attenborough RD, Marlowe FW (2018) A noisy signal: to what extent are Hadza hunting reputations predictive of actual hunting skills? Evol Human Behav 39(6):639-651. https://doi.org/10.1016/j. evolhumbehav.2018.06.005

Stubbersfield JM, Tehrani JJ, Flynn EG (2014) Serial killers, spiders and cybersex: Social and survival information bias in the transmission of urban legends. $\mathrm{Br}$ J Psychol 106(2):288-307. https://doi.org/10.1111/bjop.12073

Tennie C, Call J, Tomasello M (2009) Ratcheting up the ratchet: on the evolution of cumulative culture. Philos Trans R Soc B: Biol Sci 364(1528):2405-2415. https://doi.org/10.1098/rstb.2009.0052

Tracy JL, Shariff AF, Zhao WY, Henrich J (2013) Cross-cultural evidence that the nonverbal expression of pride is an automatic status signal. J Exp PsycholGeneral 142(1):163-180. https://doi.org/10.1037/a0028412

van der Vegt GS, Bunderson JS, Oosterhof A (2006) Expertness diversity and interpersonal helping in teams: why those who need the most help end up getting the least. Acad Manag J 49(5):877-893. https://doi.org/10.5465/ amj.2006.22798169

Verpooten J (2018) Expertise affects aesthetic evolution in the domain of art. In Kapoula Z, Volle E, Renoult J, Andreatta M (Eds.) Exploring transdisciplinarity in art and sciences. Springer International Publishing, Cham, p 303-326

Verpooten J, Dewitte S (2017) The conundrum of modern art. Human Nat 28 (1):16-38. https://doi.org/10.1007/s12110-016-9274-7

Von Rueden C, Gurven M, Kaplan H (2008) The multiple dimensions of male social status in an Amazonian society. Evol Human Behav 29(6):402-415. https://doi.org/10.1016/j.evolhumbehav.2008.05.001

von Rueden C, Gurven M, Kaplan H (2010) Why do men seek status? Fitness payoffs to dominance and prestige. Proc R Soc B https://doi.org/10.1098/ rspb.2010.2145

von Rueden C, Jaeggi AV (2016) Men's status and reproductive success in 33 nonindustrial societies: Effects of subsistence, marriage system, and reproductive strategy. Proc Natl Acad Sci USA 113(39):10824-10829. https://doi. org/10.1073/pnas.1606800113

Willer R (2009) Groups reward individual sacrifice: the status solution to the collective action problem. Am Sociol Rev 74(1):23-43

Wood LA, Kendal RL, Flynn EG (2012) Context-dependent model-based biases in cultural transmission: children's imitation is affected by model age over model knowledge state. Evol Human Behav 33(4):387-394. https://doi.org/ 10.1016/j.evolhumbehav.2011.11.010

Wood LA, Kendal RL, Flynn EG (2013) Whom do children copy? Model-based biases in social learning. Dev Rev 33(4):341-356. https://doi.org/10.1016/j. dr.2013.08.002 


\section{Acknowledgements}

This research was supported by the Leverhulme Trust (grant RPG-2016-122658 awarded to AM). We thank Stefan Gehrig, Lotty Brand, and Matt Gobel for useful comments on earlier versions of the manuscript.

\section{Additional information}

Competing interests: The authors declare no competing interests.

Reprints and permission information is available online at http://www.nature.com/ reprints

Publisher's note: Springer Nature remains neutral with regard to jurisdictional claims in published maps and institutional affiliations. (c) (i) Open Access This article is licensed under a Creative Commons Attribution 4.0 International License, which permits use, sharing, adaptation, distribution and reproduction in any medium or format, as long as you give appropriate credit to the original author(s) and the source, provide a link to the Creative Commons license, and indicate if changes were made. The images or other third party material in this article are included in the article's Creative Commons license, unless indicated otherwise in a credit line to the material. If material is not included in the article's Creative Commons license and your intended use is not permitted by statutory regulation or exceeds the permitted use, you will need to obtain permission directly from the copyright holder. To view a copy of this license, visit http://creativecommons.org/ licenses/by/4.0\%

(C) The Author(s) 2019 